\title{
Mechanical properties of PET composites using multi- walled carbon nanotubes functionalized by inorganic and itaconic acids
}

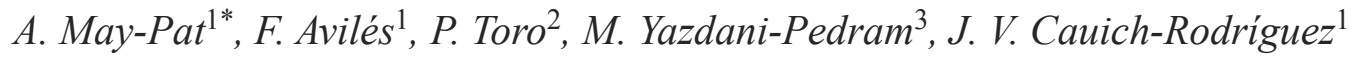 \\ ${ }^{1}$ Centro de Investigación Científica de Yucatán, A.C., Unidad de Materiales, Calle 43 \# 130, Col. Chuburná de Hidalgo, \\ 97200, Mérida, Yucatán, México \\ ${ }^{2}$ Facultad de Ciencias Físicas y Matemáticas, Universidad de Chile, Santiago, Chile \\ ${ }^{3}$ Facultad de Ciencias Químicas y Farmacéuticas, Universidad de Chile, Santiago, Chile
}

\begin{abstract}
Multi-walled carbon nanotubes (MWCNTs) were oxidized by two different acid treatments and further functionalized with itaconic acid (IA). The functionalized MWCNTs were used to fabricate Poly(ethylene terephthalate) (PET) composites by melt mixing. The presence of functional groups on the surface of the treated MWCNTs was confirmed by infrared spectroscopy and thermogravimetric analysis. The MWCNTs oxidized with a concentrated mixture of $\mathrm{HNO}_{3}$ and $\mathrm{H}_{2} \mathrm{SO}_{4}$ exhibited more oxygen containing functional groups $(\mathrm{OH}, \mathrm{COOH})$ but also suffer larger structural degradation than those oxidized by a mild treatment based on diluted $\mathrm{HNO}_{3}$ followed by $\mathrm{H}_{2} \mathrm{O}_{2}$. PET composites were fabricated using the oxidized-only and oxidized followed by functionalization with IA MWCNTs. PET composites fabricated with MWCNT oxidized by mild conditions showed improved tensile strength and failure strain, while harsh MWCNT oxidation render them overly brittle.
\end{abstract}

Keywords: polymer composites, nanocomposites, mechanical properties, MWCNTs, itaconic acid

\section{Introduction}

Poly(ethylene terephthalate) (PET) is a semicrystalline polymer which has good mechanical properties, chemical resistance, thermal stability, melt viscosity, and spinnability (ability to be spun, e.g. in the form of fibers). PET has been used in diverse fields such as food packaging, film technology, automotive, electrical, beverages and containers, and textile fiber industries, and even in the biomedical field as Dacron $[1,2]$. A way to further improve the properties of this commodity polymer is through the formation of a nanocomposite, which can be achieved by the addition of nanoclays, carbon nanotubes or other nanostructures. Nanocomposite materials often possess a combination of physical prop- erties that are not present in conventional polymer matrix composites. Because of their high aspect ratios, adding low concentrations of carbon nanotubes (CNTs) into a polymer matrix can improve the mechanical, thermomechanical and electrical properties of these polymer composite materials [3, 4]. Two key issues necessary to achieve superior performance in CNT filled polymer composites are an homogeneous distribution and dispersion of the CNTs inside the polymer matrix and a strong interaction between the CNTs and matrix. One of the most common methods used to disperse CNTs in a thermoplastic polymer matrix is melt blending [5]. Melt blending is a convenient method to produce CNT based composites given its cost effectiveness 
and ease of production, with the additional advantage of being a solvent-free process $[6,7]$. The use of this polymer processing technique to fabricate CNT-polymer composites has been reported for a large variety of polymers, including PMMA, polyolefins (PE, PP), polyamides, polyesters (PET, PBT), polyurethanes, and polystyrene [8-10]. Melt blending, however, may be limited to low CNT concentrations due to the high viscosity of the composites at high nanotube loadings and problems of dispersing the nanotubes for high CNT concentrations [11]. Regarding the issue of promoting interfacial interactions between the CNT and thermoplastic polymer matrices, the most common procedures used for covalent attachment of reactive groups to the CNT surface are treatments based on inorganic acids $[5,12]$. Usually, the nanotubes are refluxed with a nitric acid solution or a mixture of nitric and sulfuric acid, sometimes concurrently with the application of high power sonication $[5,13,14]$. These oxidative treatments usually result in formation of surface reactive groups, such as hydroxyl, carbonyl and carboxylic acid, with the drawback of producing CNT structural damage and length shortening [15]. Oxidation of multiwalled carbon nanotubes (MWCNTs) starts at the tips and gradually moves towards the central part of the tube, but, if the acid concentration is too high or the exposure time is long, some of the layers can be substantially roughened or even removed successively [15-17]. Another method which has been less explored to promote chemical bonding between CNTs and thermoplastic polymers is CNT functionalization with organic acids $[18,19]$. For the case of MWCNT/PET composites, only scant research has been conducted on the functionalization of carbon nanotubes with organic acids and compounds [20-22]. Jin and coworkers [21] functionalized MWCNTs with acetic anhydride, which resulted in good dispersion of MWCNTs in a PET matrix, as well as an increased tensile strength and elastic modulus. Yoo et al. [22] functionalized MWCNTs with benzyl and phenyl isocyanates, and found that the resulting nanocomposites showed improved dispersion of nanotubes in the PET matrix. Improved mechanical properties were found in the nanocomposites fabricated with MWCNT-phenyl isocyanate because of the favorable presence of $\pi-\pi$ interaction. Regarding itaconic acid, this organic compound has been used as compatibilizer for blends of thermoplastic polymers [23, 24]. Yazdani-Pedram et al. [23] used PP functionalized with itaconic acid as compatibilizer in blends of PP/PET. They found that the presence of modified PP improves the tensile mechanical properties of PP/PET blends. Sailaja and Seetharamu [24] used grafted low density polyethylene (LDPE) with itaconic acid in mixtures of LDPE/starch and found that LDPE/starch blends compatibilized by itaconic acid exhibited better mechanical properties as compared to their uncompatibilized counterparts. Research on functionalization of CNTs with itaconic acid for polymer composites was not found in the literature search conducted by the authors.

Therefore, the aim of the present work is to modify the surface of MWCNTs by the introduction of hydroxyl groups through treatments based on nitric and sulfuric acids, as well as itaconic acid (IA). In particular, the influence of a mild and an aggressive acid oxidation and the effect of a subsequent functionalization of the MWCNTs with IA on the tensile mechanical properties of MWCNT/PET composites is investigated.

\section{Materials and methods}

\subsection{Materials}

The MWCNTs used in this work were purchased from Bayer MaterialScience (Leverkusen, Germany). The CNT product (Baytubes $\mathrm{C}_{150 \mathrm{P}^{\circledR}}$ ) consist of MWCNTs synthesized by chemical vapor deposition with high purity ( $\sim 95 \%)$, an outer mean diameter of $13-16 \mathrm{~nm}$, inner diameter of $\sim 4 \mathrm{~nm}$ and average length of $1-4 \mu \mathrm{m}$ [15]. Nitric acid $\left(\mathrm{HNO}_{3}\right.$, $68 \% \mathrm{v} / \mathrm{v})$, sulfuric acid $\left(\mathrm{H}_{2} \mathrm{SO}_{4}, 98 \% \mathrm{v} / \mathrm{v}\right)$ and itaconic acid were purchased from Sigma Aldrich Corporation (Milwaukee, USA). The polymer used in this work is CLEARTUF 8006 Polyester Resin ('M \& G Group' Polymers USA, LLC). CLEARTUF 8006 is a high molecular weight polyethylene terephthalate thermoplastic polymer with intrinsic viscosity of $0.80 \mathrm{dl} / \mathrm{g}$ and a melting point of $250^{\circ} \mathrm{C}$.

\subsection{Oxidation of MWCNTs}

Chemical oxidation was carried out using two acid treatments, one ('mild') which is expected to be gentle with the MWCNTs surface and cause minimum structural damage and a second one which is significantly more aggressive. The 'mild' treatment consisted of oxidizing the nanotubes with nitric 
Table 1. Identification of chemical treatments investigated in this work

\begin{tabular}{|c|l|}
\hline Label & \multicolumn{1}{|c|}{ Treatment } \\
\hline A & Untreated (as-received) \\
\hline B & $\mathrm{HNO}_{3}(3.0 \mathrm{M})$ followed by $\mathrm{H}_{2} \mathrm{O}_{2}(30 \% \mathrm{v} / \mathrm{v})$ \\
\hline C & Mixture of $\mathrm{HNO}_{3}(68 \% \mathrm{v} / \mathrm{v})$ and $\mathrm{H}_{2} \mathrm{SO}_{4}(98 \% \mathrm{v} / \mathrm{v})$ \\
\hline D & Treatment $\mathrm{B}+$ Itaconic acid \\
\hline E & Treatment C + Itaconic acid \\
\hline
\end{tabular}

acid (3.0 M) followed by hydrogen peroxide [14]. The 'aggressive' treatment was conducted using a concentrated combination of nitric $(68 \% \mathrm{v} / \mathrm{v})$ and sulfuric $(98 \% \mathrm{v} / \mathrm{v})$ acids. Table 1 illustrates the treatments carried out. Label ' $A$ ' is used for asreceived (untreated) MWCNTs, taken as a reference. Treatment ' $\mathrm{B}$ ' is used for MWCNTs treated with nitric acid (3.0 M) followed by $\mathrm{H}_{2} \mathrm{O}_{2}$. This treatment was conducted by mechanically stirring the CNTs in the nitric acid for $15 \mathrm{~min}$, and then sonicating the $\mathrm{CNTs} / \mathrm{HNO}_{3}$ solution for $2 \mathrm{~h}$ in a conventional ultrasonic bath. After exhaustive washing of the CNTs with distilled water, the nitric acid was replaced with hydrogen peroxide $(30 \% \mathrm{v} / \mathrm{v})$ and the process was repeated. For treatment ' $\mathrm{C}$ ', the asreceived MWCNTs were mixed with sulfuric $(20 \mathrm{ml})$ and nitric $(20 \mathrm{ml})$ acids, in concentrations of 98 and $68 \% \mathrm{v} / \mathrm{v}$ respectively, and initially sonicated for $10 \mathrm{~min}$. The mixture was then refluxed for $1 \mathrm{~h}$ at $140^{\circ} \mathrm{C}$. Acid oxidized MWCNTs were finally obtained by washing and filtering the mixture with distilled water and then drying in a vacuum oven at $60^{\circ} \mathrm{C}$ for $48 \mathrm{~h}$.

\subsection{Functionalization with itaconic acid}

The oxidized MWCNTs (treatments B and C in Table 1) were further functionalized with itaconic acid as follows. First, oxidized MWCNTs were dispersed in $20 \mathrm{ml}$ of acetone for $10 \mathrm{~min}$ in a conventional ultrasonic bath. After $10 \mathrm{~min}$, itaconic acid $(3.0 \mathrm{~g}), \mathrm{p}$-toluenesulfonic acid as catalyst $(0.2 \mathrm{~g})$ and $80 \mathrm{ml}$ of acetone were added to the initial MWCNT/acetone mixture and stirred under reflux for $3 \mathrm{~h}$ at $60^{\circ} \mathrm{C}$. After this, the functionalized nanotubes were washed, filtered with acetone and then dried at $60^{\circ} \mathrm{C}$ in a vacuum oven to constant weight. An identical procedure with IA was conducted for MWCNTs that were previously oxidized by treatments B and C. The MWCNTs functionalized by IA that had been previously oxidized by treatment $\mathrm{B}$

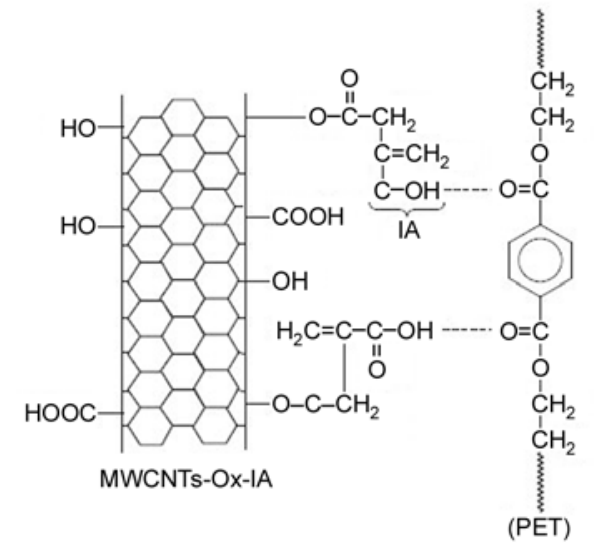

Figure 1. Proposed reaction between IA, MWCNTs and PET

were labeled as ' $D$ ', while those that were previously oxidized by treatment $\mathrm{C}$ were labeled as ' $\mathrm{E}$ ' (see Table 1). A schematic of the proposed reaction between the CNT, IA and PET is shown in Figure 1. Overall, it is expected that the $\mathrm{COOH}$ groups generated on the CNT surface are more prone to form strong bonding with the $\mathrm{C}=\mathrm{O}$ groups of PET than the $\mathrm{OH}$ ones, due to their ability to induce dimer formation. However, ester formation is also possible.

\subsection{Preparation of MWCNT/PET composites}

MWCNT/PET composites were fabricated by melt blending. Initially, PET powder was dried at $120^{\circ} \mathrm{C}$ for $24 \mathrm{~h}$ in a convection oven. Nanocomposites of $0.5 \mathrm{wt} \%$ were prepared by melt mixing the MWCNTs and PET powder in a Banbury mixing chamber (Plasticorder PL330, G.W. Brabender, Hackensack, NJ, USA.), with a volumetric capacity of $50 \mathrm{~cm}^{3}$ at $250^{\circ} \mathrm{C}$. The mixing process was performed in two continuous steps. First, the MWCNT/PETs powder material was placed inside the chamber and mixed for $5 \mathrm{~min}$ at $20 \mathrm{rpm}$. The mixing speed was then increased to $60 \mathrm{rpm}$ for $5 \mathrm{~min}$ more. The PET/ MWCNTs composite material was then laminated by compression molding into thin sheets of $110 \times$ $110 \times 1.0 \mathrm{~mm}$. The lamination process was performed at $270^{\circ} \mathrm{C}$ in a laboratory press with temperature control (Carver Laboratory Press) using 2 tons of pressure for $20 \mathrm{~min}$ and then water-cooled down to room temperature. After lamination, dog-boneshaped tensile samples were cut from the $1 \mathrm{~mm}$ thick sheet with the geometry according to ASTM D638 standard [25]. 


\subsection{Characterization}

\subsubsection{Characterization of functionalized MWCNTs}

Infrared spectroscopy of as-received and chemically functionalized MWCNTs was conducted using a Fourier transform infrared spectrometer (FT-IR) Nicolet-Protege 460, in the spectral range from 4000 to $500 \mathrm{~cm}^{-1}$. FT-IR spectra were obtained using $\mathrm{KBr}$ discs containing a very small amount of MWCNTs.

Thermogravimetric analysis (TGA) was conducted in nitrogen atmosphere with a heating rate of $10^{\circ} \mathrm{C} /$ min using a Perkin-Elmer TGA7 equipment within a temperature range of $50-750^{\circ} \mathrm{C}$. The TGA was repeated three times to yield reproducible results.

The morphology of the acid-MWCNTs was observed using an FEI-TITAN transmission electron microscope (TEM) operated at $300 \mathrm{kV}$ and registered near the Scherzer focus. TEM samples were prepared on lacey carbon grids using dispersion in an ultrasonic bath for 30 minutes.

\subsubsection{Characterization of nanocomposites}

Tensile properties of MWCNT/PETs composites were determined according to the ASTM D638 standard using type IV specimens [25]. Tensile tests were conducted in a Shimadzu AGI-100 universal testing machine equipped with a $500 \mathrm{~N}$ load cell and using a cross-head speed of $5 \mathrm{~mm} / \mathrm{min}$. Ten replicates for each nanocomposite material investigated were tested.

The fracture surfaces specimens of the tested nanocomposites were examined by using a JEOL 6360LV scanning electron microscope (SEM), after coating the surface with a thin layer of gold.

\section{Results and discussion}

\subsection{Characterization of MWCNTs}

\subsubsection{FT-IR spectroscopy}

FTIR spectroscopy was used to confirm the presence of hydroxyl, carboxyl as well as itaconic acid units on the surface of MWCNTs. As seen in Figure 2A, the IR spectrum of as-received MWCNTs shows characteristic bands due to $\mathrm{O}-\mathrm{H}$ stretching vibration at $3440 \mathrm{~cm}^{-1}, \mathrm{C}=\mathrm{C}$ stretching at $1629 \mathrm{~cm}^{-1}$ as well as $\mathrm{O}-\mathrm{H}$ bending $\left(\sim 1400 \mathrm{~cm}^{-1}\right)$ and $\mathrm{C}-\mathrm{O}$ stretching $\left(\sim 1116 \mathrm{~cm}^{-1}\right)$. The spectrum of oxidized MWCNTs by using the mild treatment (Figure 2B) shows additional absorption bands at $1736 \mathrm{~cm}^{-1}$ due to carbonyl stretching vibration of hydrogen bonded - $\mathrm{COOH}$ groups as well as an increase of the relative intensity of $\mathrm{OH}$ groups, confirming the presence of different type of hydroxyl groups on the surface of the MWCNTs. The spectrum of MWCNTs oxidized by treatment $\mathrm{C}$ (Figure 2C) is similar to that of the mild treatment (Figure 2B) but the band corresponding to $\mathrm{C}-\mathrm{O}$ stretching is more intense and better resolved. This suggests that although the same functional groups are generated for both oxidation treatments (B and C), a larger number of such functional groups should be present in the MWCNTs oxidized by the method C. Functionalization of oxidized MWCNTs by itaconic acid (Figures $2 \mathrm{D}$ and $2 \mathrm{E}$ ) show an increase in the relative intensity of the band in the region $3130 \mathrm{~cm}^{-1}$ due to $-\mathrm{OH}$ groups. The $\mathrm{C}=\mathrm{O}$ absorption bands characteristic of carboxyl functional groups $(-\mathrm{COOH})$ of itaconic acid is now markedly observed around 1707$1730 \mathrm{~cm}^{-1}$, which confirm the success of the functionalization treatment with itaconic acid.

\subsubsection{Thermogravimetric analysis}

TGA in nitrogen atmosphere was conducted for all MWCNTs examined in Table 1, as well as for IA. The thermograms obtained are presented in Figure 3. It is observed that the most thermally stable material is the as-received MWCNTs (A), which loses only about $1 \%$ weight after being heated to $750^{\circ} \mathrm{C}$. This high thermal stability is due to the low content of amorphous carbon in the as-received material. When a mild oxidation is conducted on the MWCNTs (B), the amount and rate of weight loss is very similar to that of the as-received material, indicating that no or very few amorphous carbon has been generated because of the acid treatment. The harsh oxidation treatment (C), on the other hand, significantly degrades the graphitic structure of the MWCNTs by converting it to amorphous carbon, which is evident by the pronounced weight loss observed early in its TGA curve. Below $150^{\circ} \mathrm{C}$ evaporation of adsorbed water is expected. The pronounced weight loss observed between $\sim 150$ and $350^{\circ} \mathrm{C}$ are attributed to elimination of hydroxyl and carboxylic functionalities present on the surface of the oxidized MWCNT probably due to dehydration and decarboxilation $[16,17]$. The fact that the weight loss in this temperature range is markedly greater 

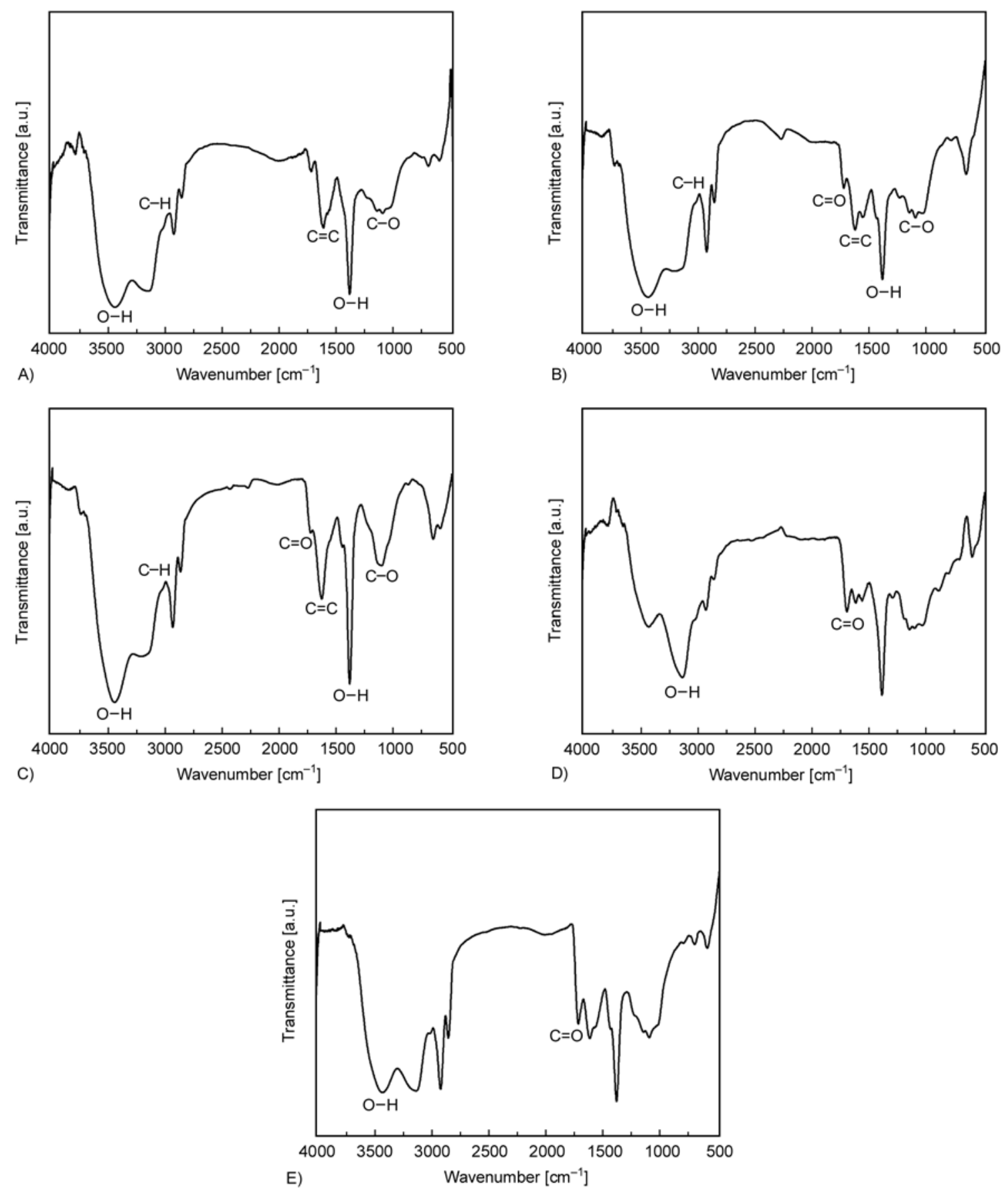

Figure 2. FT-IR spectra of MWCNTs. Treatment A, B, C, D and E refer to Table 1.

for sample $\mathrm{C}$ than $\mathrm{B}$ indicates that a larger number of functionalities are present in the MWCNTs oxidized by the aggressive treatment, with respect to the ones oxidized under mild conditions. For temperatures above $350^{\circ} \mathrm{C}$, a large amount of weight is lost by MWCNTs oxidized by treatment $\mathrm{C}$, which indicates that this treatment has converted part of the CNT graphitic structure to amorphous carbon, which is thermally oxidized slightly above $350^{\circ} \mathrm{C}$.
The MWCNTs that were functionalized by IA after oxidation present a distinctive behavior. For the MWCNTs previously oxidized by treatment B and then functionalized by IA (D), a marked weight loss occurs around $200^{\circ} \mathrm{C}$, which matches with the decomposition of the IA (see curve for IA in Figure 3). After thermal decomposition of the IA bonded to the CNT, the curve of sample D follows a slope (rate of weight loss) similar to that of the 

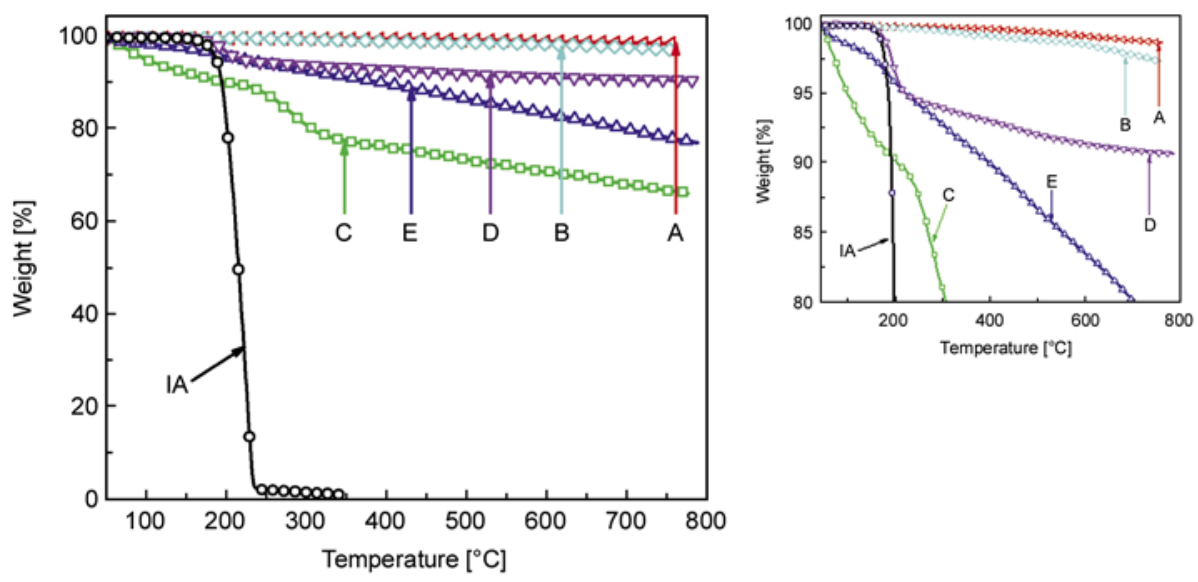

Figure 3. TGA curves of MWCNTs samples. Labels refer to Table 1.

curve corresponding to the sample that was only oxidized with the same treatment (B). The behavior of the MWCNTs that were functionalized with IA after oxidation with an aggressive acid treatment (samples E) was different. In this case, a larger weight loss was observed with respect to samples oxidized by treatment $\mathrm{D}$ for all temperature ranges examined. The rate of weight loss (slope of the curve) is markedly smaller for samples $\mathrm{E}$ than for $\mathrm{C}$ before $350^{\circ} \mathrm{C}$, but after $350^{\circ} \mathrm{C}$ both slopes were similar. The smaller mass loss of sample E compared to sample $\mathrm{C}$ may suggest that some of the amorphous carbon generated during the harsh CNT oxidation by method $\mathrm{C}$ is physically removed during the subsequent treatment with IA. This will be further examined in connection to the mechanical properties of the composites in section 3.2.1.

Therefore, from the TGA analysis it is concluded that an aggressive acid oxidation treatment (such as C) generates a larger concentration of functional groups on the surface of the MWCNTs with respect to a milder oxidation treatment (B), but also destroys a great deal of the graphitic structure converting it to amorphous carbon. The TGA curves of MWCNTs that were functionalized with IA confirm the presence of IA on the CNT, which is indicative of an adequate functionalization process.

\subsubsection{Transmission electron microscopy}

TEM analysis of the as-received (A) and oxidized samples (B and C) is shown in Figure 4. No images are presented for treatments with IA since no new particular features are expected after functionalization with IA. Figure 4a reveals the morphology of an individual as-received multi-walled carbon nan- otube. The as-received material is featured by the characteristic graphitic layers arranged in a coaxial cylindrical fashion. Some amorphous carbon is observed at the outermost layers and structural defects are also present in the as-received material. The morphology of the MWCNTs oxidized by a sequential treatment based on diluted $\mathrm{HNO}_{3}$ followed by $\mathrm{H}_{2} \mathrm{O}_{2}$ (treatment $\mathrm{B}$, Figure $4 \mathrm{~b}$ ) is similar to that of the as-received MWCNTs, indicating that structural damage is either absent or small. For the MWCNTs oxidized by the concentrated mixture of $\mathrm{HNO}_{3}$ and $\mathrm{H}_{2} \mathrm{SO}_{4}$ (treatment $\mathrm{C}$ ), the CNTs exhibit severe structural damage, as shown in Figure 4c. This concentrated mixture of acids causes conversion of the original graphitic structure to amorphous carbon with the consequent increase in CNT roughness and waviness as observed in Figure 4c. In this case, the damage reaches even the inner nanotube walls. Treating the MWCNTs with a concentrated mixture of $\mathrm{HNO}_{3}$ and $\mathrm{H}_{2} \mathrm{SO}_{4}$ causes severe etching of the graphitic surface of the CNT, leading to defective tubes with a large population of disordered sites and amorphous carbon. These TEM observations are consistent with the thermal degradation evidenced by the thermogram of treatment $\mathrm{C}$ in Figure 3. On the other hand, the MWCNT oxidation with a mild treatment such as B yielded no or few structural damage, which is also consistent with the TGA findings. However, FT-IR analysis (Figure 2) suggests that more functional groups are present on MWCNTs oxidized by treatment C than for B. For the improvement of the composite mechanical properties, structurally pristine CNTs with a large density of functionalities are desirable. In our case, MWCNTs oxidized by treatment $\mathrm{C}$ have a large 


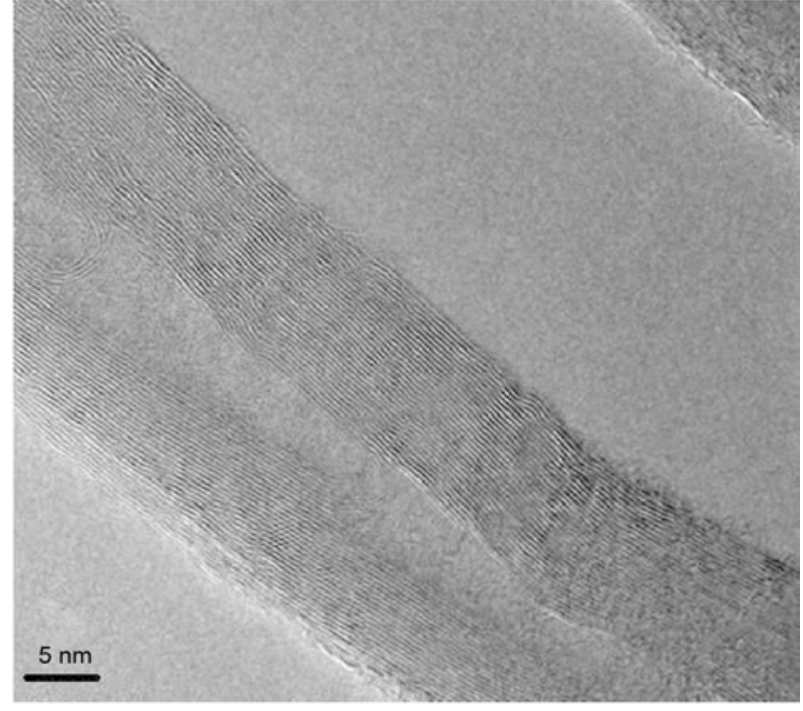

a)

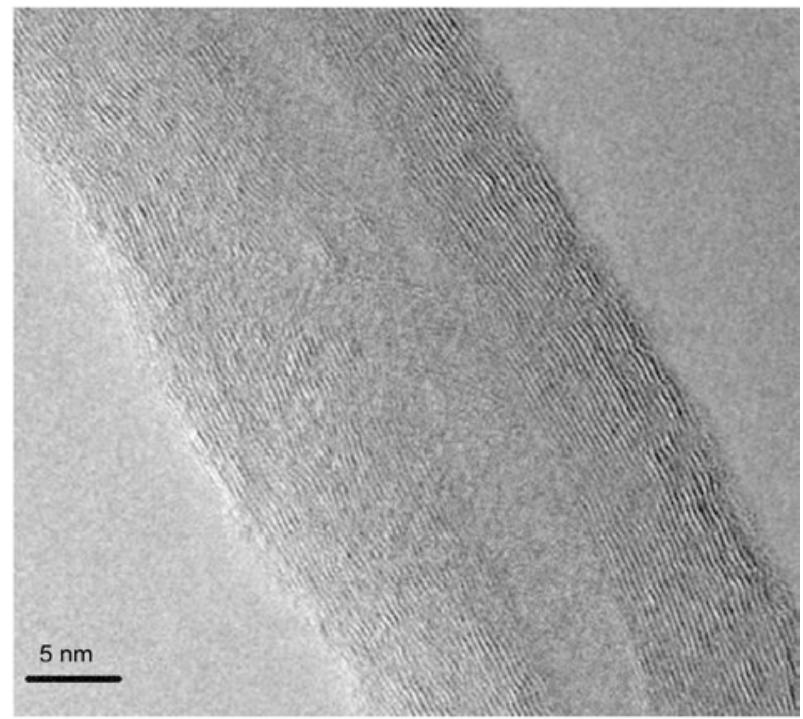

b)

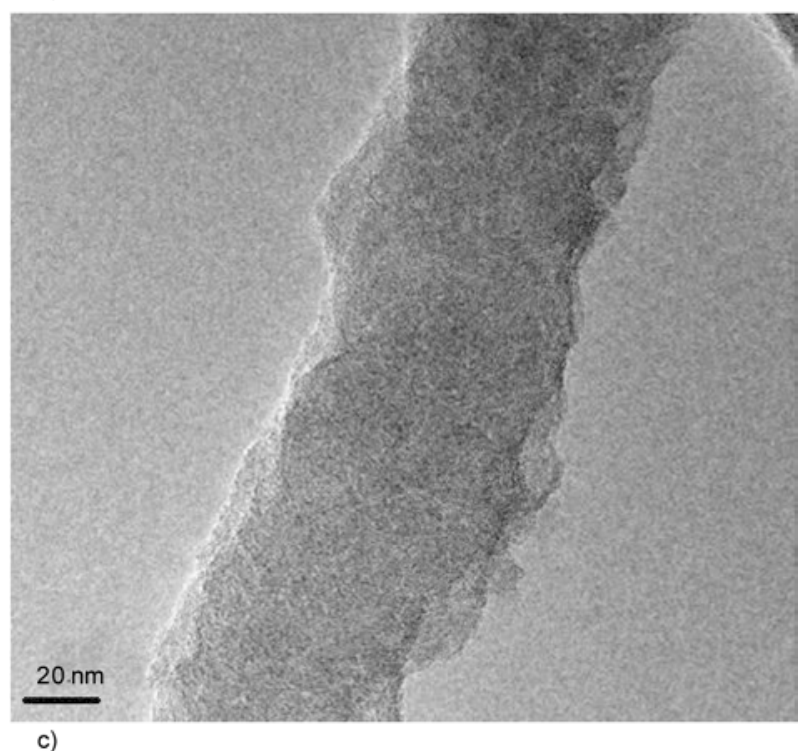

Figure 4. TEM of MWCNTs. a) As-received (A), b) oxidized by $\mathrm{HNO}_{3}$ followed by $\mathrm{H}_{2} \mathrm{O}_{2}(\mathrm{~B})$, c) oxidized by a concentrated mixture of $\mathrm{HNO}_{3}$ and $\mathrm{H}_{2} \mathrm{SO}_{4}(\mathrm{C})$. number of $\mathrm{OH}$ and $\mathrm{COOH}$ functionalities, but also are severely damaged. On the other hand, the MWCNTs oxidized by treatment B were not severely damaged by the oxidizing treatment, but they also have less density of functional groups than those oxidized by treatment $\mathrm{C}$. The effect of these competing factors on the mechanical properties of the composites fabricated with these MWCNTs will be examined in the next section.

\subsection{Characterization of nanocomposites \\ 3.2.1. Tensile properties}

The tensile stress-strain curves of pure PET and the examined MWCNT/PET composites at $0.5 \mathrm{wt} \%$ loading are presented in Figure 5. Table 2 presents a summary of the measured mechanical properties, where average and standard deviations are reported. The stress-strain curves and measured mechanical properties (Table 2) are similar for MWCNT/PET composites which used as-received MWCNTs (MWCNT/PETs-A) to those of PET, motivating the need of CNT functionalization. The absence of significant improvements in the mechanical properties

Table 2. Mechanical properties of tested MWCNT/PET composites

\begin{tabular}{|l|c|c|c|}
\hline \multicolumn{1}{|c|}{ Sample } & $\begin{array}{c}\text { Tensile } \\
\text { strength } \\
{[\mathbf{M P a}]}\end{array}$ & $\begin{array}{c}\text { Elastic } \\
\text { modulus } \\
\text { [GPa] }\end{array}$ & $\begin{array}{c}\text { Failure } \\
\text { strain [\%] }\end{array}$ \\
\hline PET & $33.9 \pm 7.06$ & $1.54 \pm 0.04$ & $2.22 \pm 0.49$ \\
\hline MWCNT/PETs-A & $34.1 \pm 6.48$ & $1.47 \pm 0.09$ & $2.35 \pm 0.43$ \\
\hline MWCNT/PETs-B & $50.0 \pm 5.30$ & $1.58 \pm 0.06$ & $3.45 \pm 0.45$ \\
\hline MWCNT/PETs-C & - & - & - \\
\hline MWCNT/PETs-D & $23.4 \pm 6.32$ & $1.39 \pm 0.15$ & $2.40 \pm 0.93$ \\
\hline MWCNT/PETs-E & $26.9 \pm 5.16$ & $1.48 \pm 0.14$ & $2.43 \pm 0.72$ \\
\hline
\end{tabular}

$-=$ Not possible to measure

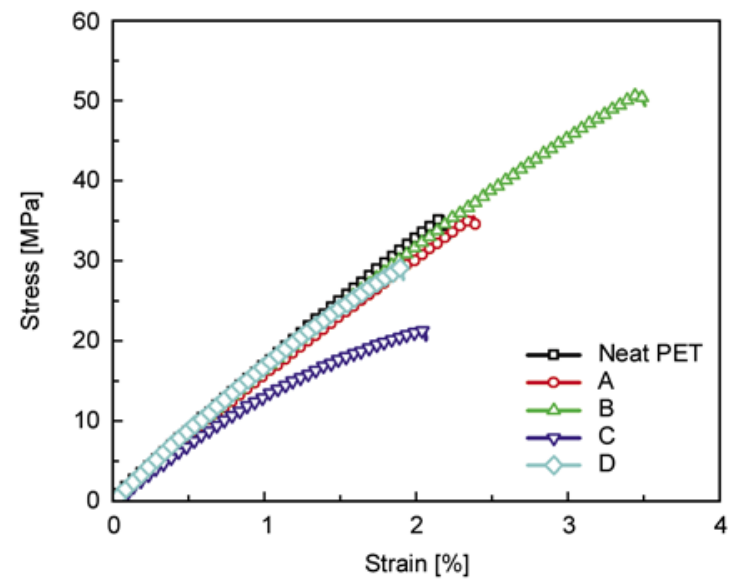

Figure 5. Representatives stress-strain curves for PET and PET nanocomposites. Labels A to E refer to Table 1. 
of the as-received CNT composites may be the result of aggregation, as well as poor interfacial interaction between the as-received MWCNTs and PET. Quite different properties are obtained for the composites whose CNTs were only oxidized by $\mathrm{HNO}_{3}$ followed by $\mathrm{H}_{2} \mathrm{O}_{2}$ (MWCNT/PETs-B). With respect to neat $\mathrm{PET}$, these composites showed an increase in the strength and failure strain of 47 and $55 \%$ (based on averages) respectively, although the improvement in elastic modulus may not be statistically significant. The large improvement in the tensile properties of the MWCNT/PETs-B composites is attributed to the improved dispersion of MWCNTs inside the matrix (which will be further examined by SEM) and improved interactions between the MWCNTs and PET mostly by hydrogen bonding, enhancing the interfacial bonding. The PET-composites that utilized MWCNTs treated by the concentrated mixture of nitric and sulphuric acids (treatment $\mathrm{C}$ ) were not possible to manufacture in the form of tensile coupons (indicated by dash lines in Table 2). These composites were very brittle and cracked in many pieces immediately after releasing from the press used for compression molding. This behavior, which was very distinctive from the rest of the composites, confirms that the MWCNTs treated by treatment $\mathrm{C}$ contain a large number of $(\mathrm{COOH})$ functionalities and that such functionalities are interacting with the PET matrix (through $\mathrm{C}=\mathrm{O}$ ) to render the composites increased brittleness and affecting its processability. These composites may also be more thermally conductive (which influence the processing parameters), since it has been shown that MWCNTs treated by strong mixtures of nitric and sulfuric acids generate a large number of hydroxyl and carboxyl functional groups which increases the thermal conductivity of the CNTs and their composites [26]. The nucleating effect of the functionalized nanotubes during the PET melt compounding [27] may also be a contributing factor for its brittleness.

The composites prepared with IA-functionalized MWCNTs (D and E) did not show improvements in their mechanical properties with respect to the neat PET. With respect to PET, the tensile strength of both composites (D and E) reduced, and the elastic modulus and failure strain remained practically unchanged, see Table 2. The decrease in tensile strength (and decreasing trend in elastic modulus)

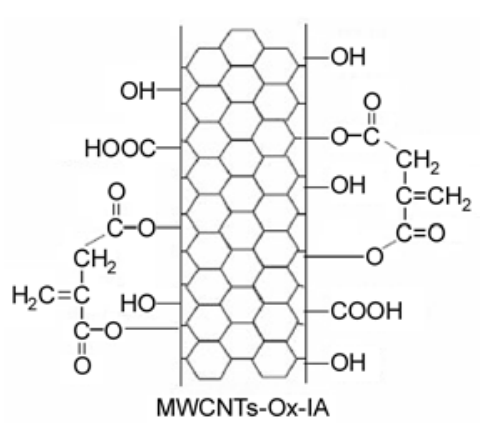

Figure 6. Possible ester formation on IA functionalized MWCNTs

of these composites could be explained by reduced interactions between the functionalized CNTs and the PET matrix and the presence of agglomerations. This would mean that a second scenario to that initially proposed in Figure 1, is also possible, which is depicted in Figure 6. Accordingly, the itaconic acid may react with the hydroxyl groups present on the acid oxidized surface of the CNT by forming ester bonds. This reduces the effective number of hydroxyl functionalities available for bonding the CNT to the polymer, leaving a hydrophobic CNT which is difficult to disperse in the hydrophilic PET.

\subsubsection{Scanning electron microscopy}

Figure 7 shows SEM fracture surfaces of MWCNT/ PET composites whose CNTs were functionalized by treatments A, B, D and E. The CNTs seem moderately well dispersed in all composites in Figure 7. Although clear differences are difficult to discern among the figures, some particular features were observed depending on the treatment. For the nontreated composites (MWCNT/PETs-A), Figure 7a, a few small aggregates of MWCNTs appeared systematically during the SEM analysis. For this composite, MWCNTs are also seen protruding the fracture plane (plane of the SEM image) suggesting a large occurrence of CNT pullout, which is consistent with a weak interfacial bonding between the nanotubes and PET. The scenario was different for MWCNT/PETs-B composites, Figure 7b. For these composites, imaging the MWCNTs in the composite was markedly more difficult than for the rest of the samples, and the few CNTs that could be imaged appeared covered by the polymer, as seen in Figure $7 \mathrm{~b}$. We believe that this particular feature relates to a better dispersion into the PET matrix, as a consequence of the oxidative treatment used. MWCNTs 


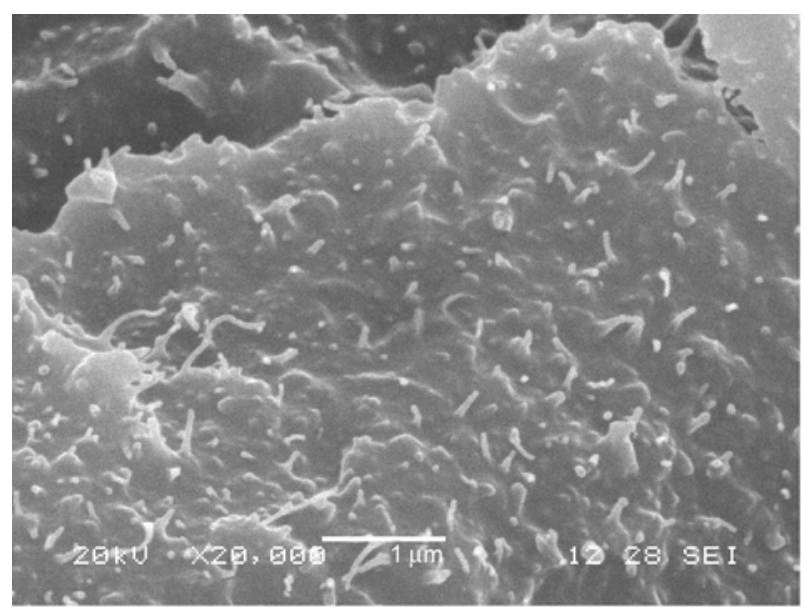

a)

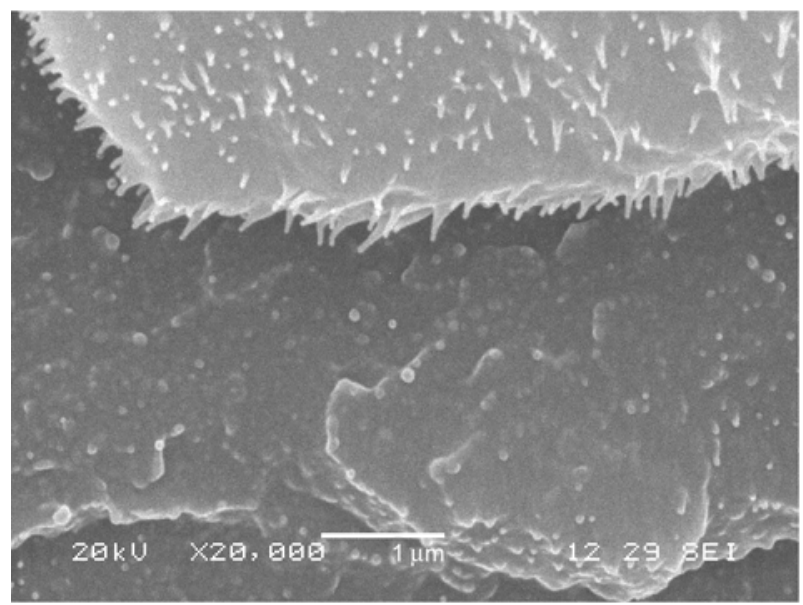

c)

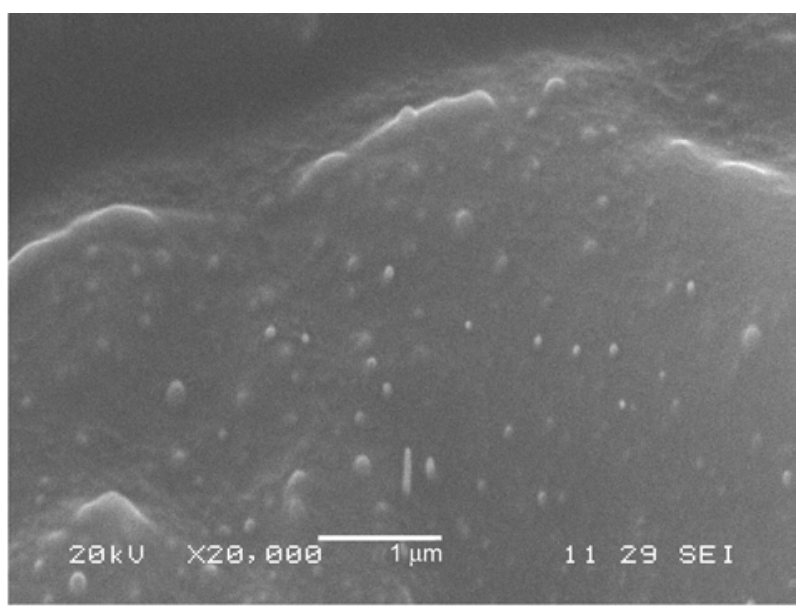

b)

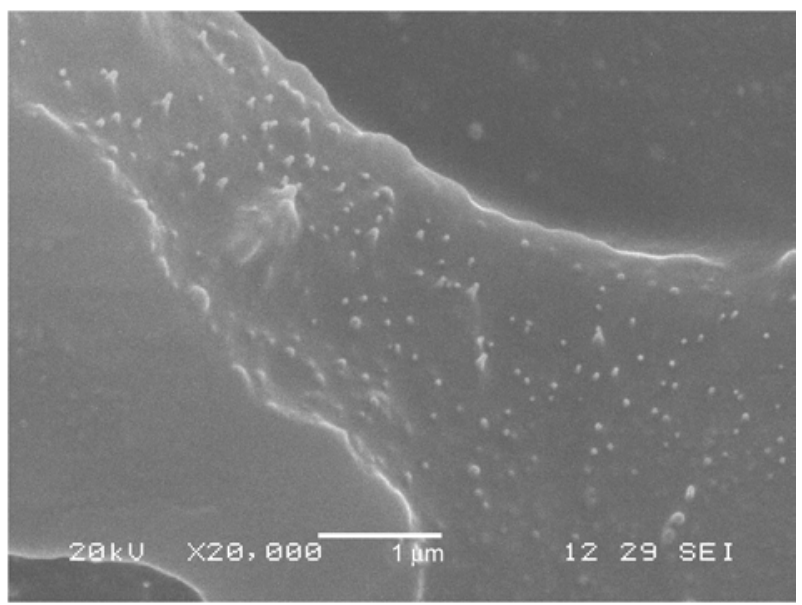

d)

Figure 7. SEM images of fractured nanocomposites. (a) MWCNT/PETs-A, (b) MWCNT/PETs-B, (c) MWCNT/PETs-D, (d) MWCNT/PETs-E. Labels refer to Table 2.

oxidized by treatment B also appeared wrapped by the PET matrix, which suggests good interfacial bonding. This finding is consistent with the results of the tensile tests, where enhanced mechanical properties were obtained for this treatment. Figures $7 \mathrm{c}$ and $7 \mathrm{~d}$ show fracture surfaces of MWCNT/ PET composites which used MWCNTs functionalized by IA after acid oxidation by mild (Figure 7c) and harsh (Figure 7d) conditions (treatments D and E in Table 2). For both cases, MWCNTs are seen clearly and moderately well dispersed into the PET matrix, but not covered by the polymer as in the case of Figure $7 \mathrm{~b}$.

\section{Conclusions}

The influence of two acid oxidation methods and further functionalization with itaconic acid to functionalize the surface of MWCNTs and improve the mechanical properties of PET composites has been examined. Two routes for acid oxidations employ- ing inorganic acids were examined, a mild one based on a sequential treatment of diluted nitric acid and hydrogen peroxide, and an aggressive one based on a concentrated mixture of nitric and sulfuric acids. Oxidizing by the mild experimental conditions proposed herein generate hydroxyl and carboxyl functional groups on the CNT surface with minimum CNT damage, which produces enhanced mechanical properties of MWCNT/PET composites. When the oxidation uses concentrated acids, a larger density of functional groups is generated, with the concomitant damage of the CNT structure. The composites manufactured using the MWCNTs oxidized by this aggressive route are overly brittle, to the extent that compromises its practical use.

For PET composites, sequential functionalization of the MWCNTs with IA after CNT oxidation is not recommended, since the $\mathrm{OH}$ groups of the IA may bond to similar acidic groups existent on the oxidized MWCNTs, reducing the density of function- 
alities available on the MWCNT surface for hydrogen bonding with the ester groups of PET. A simple oxidation of the MWCNTs using nitric acid and hydrogen peroxide in mild experimental conditions is enough to significantly improve the tensile properties of the composite.

\section{Acknowledgements}

This work is part of an international project between Mexico and Chile (CIAM) sponsored by CONACYT-Mexico (projects No. 105567 and 79609) and CONICYT-Chile (project FONDECYT No.1090260). The authors also wish to thank Santiago Duarte and Dr. Arturo Ponce for the SEM and TEM analyses.

\section{References}

[1] Van Krevelen D. W.: Properties of polymers, Elsevier, Amsterdam (1997).

[2] Cowie J. M. G.: Polymers: chemistry and physics of modern materials. Taylor and Francis Group, Boca Raton (2008).

[3] Kim J. K., Park H. S., Kim S. H.: Multiwall-carbonnanotube-reinforced poly(ethylene terephthalate) nanocomposites by melt compounding. Journal of Applied Polymer Science, 103, 1450-1457 (2007). DOI: $10.1002 / a p p .25377$

[4] Zhu Z., Wang R., Dong Z., Huang X., Zhang D.: Morphology, crystallization, and mechanical properties of poly(ethylene terephthalate)/multiwalled carbon nanotubes composites. Journal of Applied Polymer Science, 120, 3460-3468 (2011).

DOI: $10.1002 /$ app.33438

[5] Ma P-C., Siddiqui N. A., Marom G., Kim J-K.: Dispersion and functionalization of carbon nanotubes for polymer-based nanocomposites: A review. Composites Part A: Applied Science and Manufacturing, 41, 13451367 (2010).

DOI: 10.1016/j.compositesa.2010.07.003

[6] Jin Z., Pramoda K. P., Goh S. H., Xu G.: Poly(vinylidene fluoride)-assisted melt-blending of multi-walled carbon nanotube/poly(methyl methacrylate) composites. Materials Research Bulletin, 37, 271-278 (2002). DOI: $10.1016 / \mathrm{S} 0025-5408(01) 00775-9$

[7] Anoop A. K., Agarwal U. S., Rani J.: Carbon nanotubes-reinforced PET nanocomposite by melt-compounding. Journal of Applied Polymer Science, 104, 3090-3095 (2007).

DOI: 10.1002/app.25674

[8] Du J-H., Bai J., Cheng H-M.: The present status and key problems of carbon nanotube based polymer composites. Express Polymer Letters, 1, 253-273 (2007). DOI: $10.3144 /$ expresspolymlett.2007.39
[9] Sorrentino A., Vertuccio L., Vittoria V.: Influence of multi-walled carbon nanotubes on the $\beta$ form crystallization of syndiotactic polystyrene at low temperature. Express Polymer Letters, 4, 339-345 (2010).

DOI: $10.3144 /$ expresspolymlett.2010.43

[10] Jin Z., Pramoda K. P., Xu G., Goh S. H.: Dynamic mechanical behavior of melt-processed multi-walled carbon nanotube/poly(methyl methacrylate) composites. Chemical Physics Letters, 337, 43-47 (2001). DOI: 10.1016/S0009-2614(01)00186-5

[11] Bikiaris D., Vassiliou A., Chrissafis K., Paraskevopoulos K. M., Jannakoudakis A., Docoslis A.: Effect of acid treated multi-walled carbon nanotubes on the mechanical, permeability, thermal properties and thermo-oxidative stability of isotactic polypropylene. Polymer Degradation and Stability, 93, 952-967 (2008).

DOI: $10.1016 /$ j.polymdegradstab.2008.01.033

[12] Pötschke P., Bhattacharyya A. R., Janke A.: Carbon nanotube-filled polycarbonate composites produced by melt mixing and their use in blends with polyethylene. Carbon, 42, 965-969 (2004). DOI: 10.1016/j.carbon.2003.12.001

[13] Saito T., Matsushige K., Tanaka K.: Chemical treatment and modification of multi-walled carbon nanotubes. Physica B: Condensed Matter, 323, 280-283 (2002).

DOI: 10.1016/S0921-4526(02)00999-7

[14] Avilés F., Cauich-Rodríguez J. V., Moo-Tah L., MayPat A., Vargas-Coronado R.: Evaluation of mild acid oxidation treatments for MWCNT functionalization. Carbon, 47, 2970-2975 (2009). DOI: $10.1016 /$ j.carbon.2009.06.044

[15] Avilés F., Ponce A., Cauich-Rodríguez J. V., Martínez G. T.: TEM examination of MWCNTs oxidized by mild experimental conditions. Fullerenes, Nanotubes and Carbon Nanostructures, 20, 49-55 (2012). DOI: $10.1080 / 1536383 X .2010 .533308$

[16] Datsyuk V., Kalyva M., Papagelis K., Parthenios J., Tasis D., Siokou A., Kallitsis I., Galiotis C.: Chemical oxidation of multiwalled carbon nanotubes. Carbon, 46, 833-840 (2008). DOI: $10.1016 /$ j.carbon.2008.02.012

[17] Rosca I. D., Watari F., Uo M., Akasaka T.: Oxidation of multiwalled carbon nanotubes by nitric acid. Carbon, 43, 3124-3131 (2005). DOI: $10.1016 /$ j.carbon.2005.06.019

[18] Wang M., Pramoda K. P., Goh S. H.: Enhancement of interfacial adhesion and dynamic mechanical properties of poly(methyl methacrylate)/multiwalled carbon nanotube composites with amine-terminated poly(ethylene oxide). Carbon, 44, 613-617 (2006). DOI: $10.1016 /$ j.carbon.2005.10.001 
[19] Lee S. H., Cho E. N. R., Jeon S. H., Youn J. R.: Rheological and electrical properties of polypropylene composites containing functionalized multi-walled carbon nanotubes and compatibilizers. Carbon, 45, 2810-2822 (2007).

DOI: $10.1016 /$ j.carbon.2007.08.042

[20] Gao Y., Wang Y., Shi J., Bai H., Song B.: Functionalized multi-walled carbon nanotubes improve nonisothermal crystallization of poly(ethylene terephthalate). Polymer Testing, 27, 179-188 (2008).

DOI: $10.1016 /$ j.polymertesting.2007.09.012

[21] Jin S. A., Yoon K. H., Park Y-B., Bang D. S.: Properties of surface-modified multiwalled carbon nanotube filled poly(ethylene terephthalate) composite films. Journal of Applied Polymer Science, 107, 1163-1168 (2008).

DOI: 10.1002/app.27153

[22] Yoo H. J., Jung Y. C., Cho J. W.: Effect of interaction between poly(ethylene terephthalate) and carbon nanotubes on the morphology and properties of their nanocomposites. Journal of Polymer Science Part B: Polymer Physics, 46, 900-910 (2008).

DOI: $10.1002 /$ polb.21424
[23] Yazdani-Pedram M., Vega H., Retuert J., Quijada R.: Compatibilizers based on polypropylene grafted with itaconic acid derivatives. Effect on polypropylene/ polyethylene terephthalate blends. Polymer Engineering and Science, 43, 960-964 (2003).

DOI: $10.1002 /$ pen.10079

[24] Sailaja R. R. N., Seetharamu S.: Itaconic acid - grafted - LDPE as compatibilizer for LDPE - plasticized Tapioca starch blends. Reactive and Functional Polymers, 68, 831-841 (2008).

DOI: $10.1016 /$ j.reactfunctpolym.2007.12.003

[25] ASTM D638-10: Standard test method for tensile properties of plastics (2002).

[26] Wang J., Xie H., Xin Z., Li Y.: Increasing the thermal conductivity of palmitic acid by the addition of carbon nanotubes. Carbon, 48, 3979-3986 (2010).

DOI: $10.1016 /$ j.carbon.2010.06.044

[27] Anoop-Anand K., Agarwal U. S., Jospeh R.: Carbon nanotubes induced crystallization of poly(ethylene terephthalate). Polymer, 47, 3976-3980 (2006).

DOI: $10.1016 /$ j.polymer.2006.03.079 